\title{
TEM Study of Weld Interface between Cu-Alloy \& Steel
}

\author{
H. Z. Wang, ${ }^{*}$ K. H. Wang, ${ }^{* *}$ R. K. Zheng, ${ }^{*}$ and S. P. Ringer* \\ * Australian Key Centre for Microscopy \& Microanalysis, The University of Sydney, NSW, 2006, \\ Australia \\ ** Department of Materials Science and Engineering, Nanjing University of Science and \\ Technology, Nanjing 210094, China
}

There has been much interest in the development of new welding technology that enables layers of $\mathrm{Cu}$ and its alloys to be fused to steel products. The challenges are formidable when it is considered that the welding methods ought generate special composite material properties to improve the electrical and/or thermal conductivity and/or modify the hardness and ductility of the surface of steel substrates [1-2] whilst providing a structurally sound join. A novel Induction-Heated Deposition of Molten-Copper (IHDMC) welding technique has been developed recently, where thin (several mm) layers of $\mathrm{Cu}$ are fused to a steel substrate with excellent cohesive as well as surface mechanical properties [3-4]. This work summarises our initial efforts to understand the origins of the apparently sound join associated with the IHDMC weld.

In this work, a block of $30 \mathrm{CrMnSi}$ steel $(\mathrm{C}-0.3, \mathrm{Cr} / \mathrm{Mn} / \mathrm{Si}<1.5$, wt. \%) that had been welded by IHDMC method to $\mathrm{H} 96 \mathrm{Cu}(\mathrm{Cu}-4 \mathrm{Zn}$, wt. \%) was studied using a JEOL JEM 3000F transmission electron microscope (TEM). Specimens were carefully excised and thinned using cross-sectional tripod polishing methods, so as to present the fusion line normal to the electron beam. Figure 1 is a bight field (BF) TEM image from the $\alpha$-ferritic steel $-\mathrm{Cu}$ alloy interface, which was observed to be thin and continuous. On closer inspection, Fig. 2, it was apparent that a there exists a discrete reaction interlayer (RI), marked 1, 2, 3, 4, 5, between the $\alpha$-ferrite and the $\mathrm{Cu}$-alloy. The high resolution TEM micrograph in Fig. 3 suggests that the RI is approximately $10 \mathrm{~nm}$ thick and can maintain a high degree of coherence between both the ferrite and the $\mathrm{Cu}$. In the development of these types of interfaces, it is suggested that the RI grows in such a way as to provide a metallurgically sound bond between the steel and the $\mathrm{Cu}$. Selected area electron diffraction in nanobeam mode was used to assess the potential for preferred orientations to develop between grains from the steel, the reaction interface and the $\mathrm{Cu}$ alloy. For this experiment, the specimen was tilted into an orientation where both the $\mathrm{Cu}$ alloy and the ferrite were both near low index orientations and patterns recorded for the three-phases. Two examples from adjacent regions of the interface are provide in Fig. 4 and demonstrate that the RI is potentially a complex body-centred-cubic structure with cell parameter $\mathrm{a}_{0}$ $=0.77 \mathrm{~nm}$. These preliminary findings require further confirmation from high angle tilting experiments. Detailed microanalysis is also in progress to follow compositional profiles through the RI. The occurrence of occasional low energy (almost rational) crystallographic interfaces such as those imaged in Figs. 3 and 4 is thought to be the origin of the excellent properties for this weld.

\section{References}

[1] V. Malin, Welding Journal. 71(5) (1992) 35.

[2] K. H. Wang, et al., ACTA Metallurgica Sinica 32(6) (1996) 653.

[3] K. H. Wang, et al., Trans. China Welding Institution 22 (2001) 69.

[4] K. H. Wang, et al., Ordnance Materials Sci. and Eng. 25 (2002) 34. 


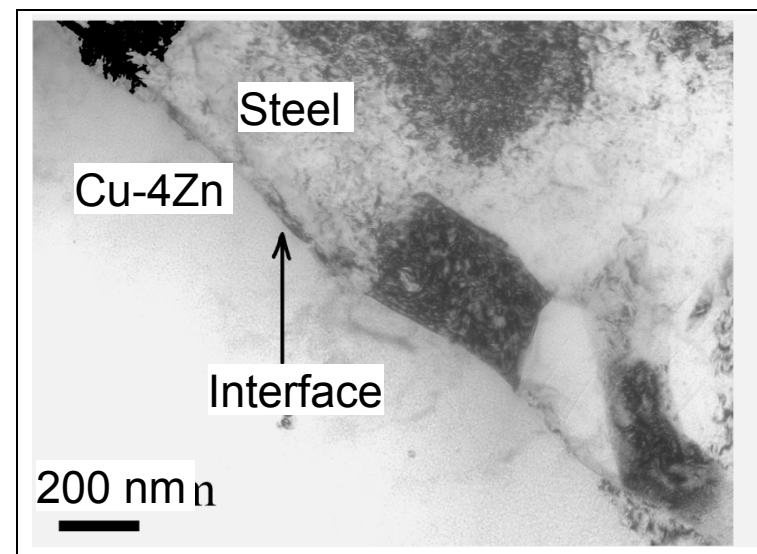

Fig. 1. TEM micrograph to the interface.

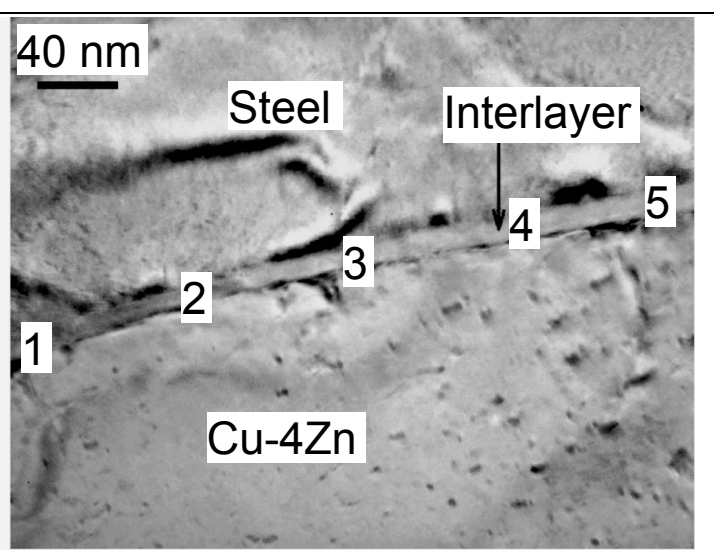

Fig. 2. TEM image of reaction interlayer

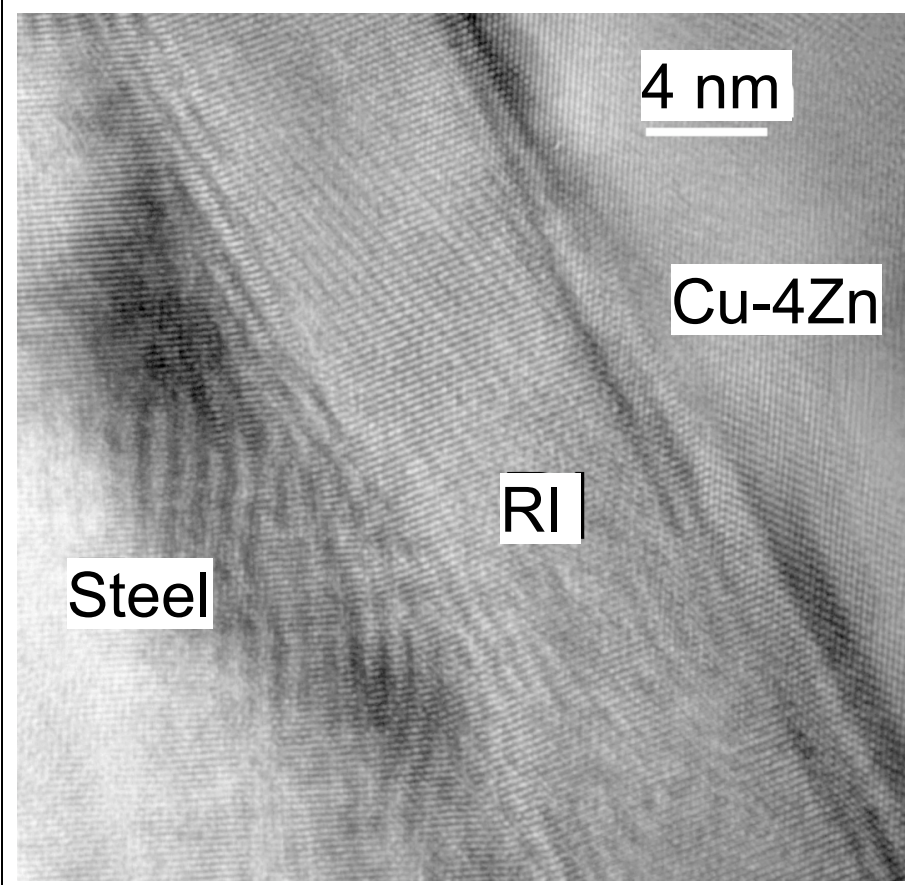

Fig. 3. HRTEM image of the reaction interlayer (RI) and its bonding with $\mathrm{Cu}-4 \mathrm{Zn}$ and Steel
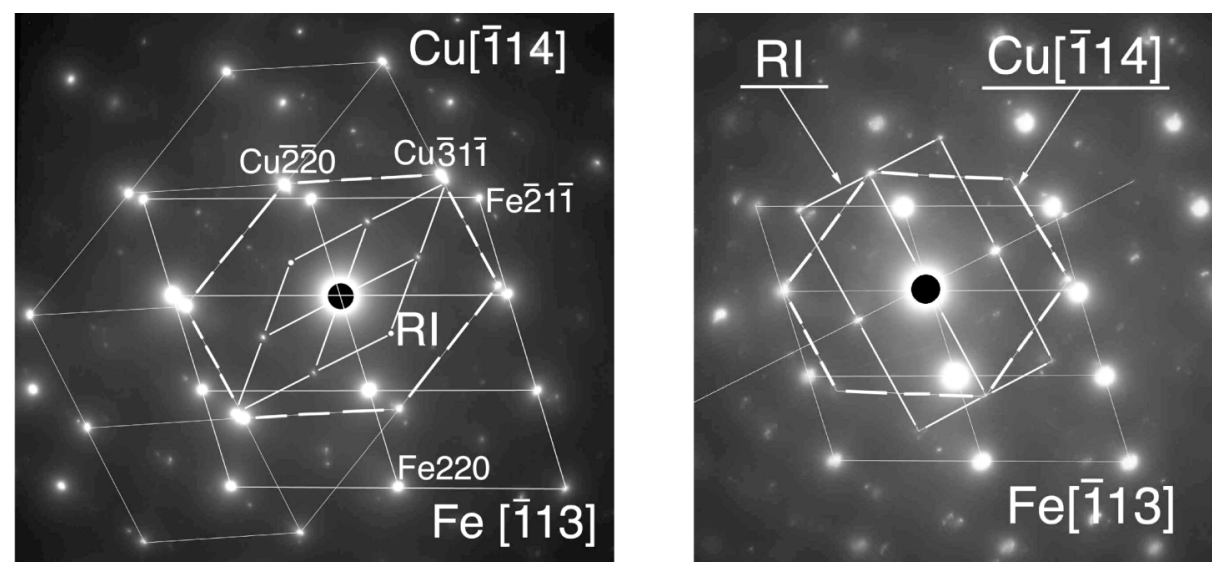

Fig. 4. Selected area diffraction patterns of RI and $\mathrm{Cu}-4 \mathrm{Zn}$ and Steel with nanobeam electron diffraction 